\title{
AVALIAÇÃO DE DESEMPENHO NA APLICAÇÃO DO CONTROLE ESTATÍSTICO DE PROCESSOS: SELEÇÃO DE REFERENCIAL TEÓRICO INTERNACIONAL E ANÁLISE BIBLIOMÉTRICA
}

\author{
PERFORMANCE EVALUATION IN THE STATISTICAL CONTROL OF PROCESSES: SELECTION OF \\ INTERNATIONAL THEORICAL FRAMEWORK AND BIBLIOMETRIC ANALYSIS
}

EVALUACIÓN DE DESEMPEÑO EN LA APLICACIÓN DEL CONTROL ESTADÍSTICO DE PROCESOS: SELECCIÓN DEL MARCO DE REFERENCIA TEÓRICO INTERNACIONAL Y ANÁLISIS BIBLIOMÉTRICO

\author{
LEONARDO ENSSLIN \\ Doutor \\ Universidade do Sul de Santa Catarina - Brasil \\ leonardoensslin@gmail.com \\ ADEMAR DUTRA \\ Doutor \\ Universidade do Sul de Santa Catarina - Brasil \\ ademar.unisul@gmail.com \\ VINÍCIUS DEZEM \\ Mestre \\ Universidade do Sul de Santa Catarina - Brasil \\ viniciusdezem@yahoo.com
}

KARINE SOMENSI Mestranda Universidade do Sul de Santa Catarina - Brasil karinesomensi@hotmail.com

Submetido em: 17/10/2016 Aprovado em: 13/09/2017

Doi: alcance.v24n3.p396-412

\section{RESUMO}

O estudo tem como objetivo identificar o que a literatura científica internacional aborda sobre o tema Avaliação de Desempenho na Gestão do Controle Estatístico de Processos (CEP), possibilitando, assim, a identificação de oportunidades de aperfeiçoamento. A pesquisa exploratória utilizou como instrumento de intervenção o ProKnow$C$ para a seleção do portfólio bibliográfico-PB e a análise das características deste fragmento da literatura. Os autores de destaque identificados foram Wen Lea Pearn, Shu-Ming Chung, com 5, 4, e 3 publicações respectivamente no PB. Foi possível também identificar os periódicos Quality and Reliability Engineering International e o Expert Systems With Applications como os dois com maior número de publicações. Já em relação às palavras-chaves presentes nos artigos do portfólio, as que se destacaram foram Process Capability Indices, Control Carts e Process Capability index. Os periódicos que apresentaram maior fator de impacto foram: European Jounal of Operational Research e Expert Systems with Applications. Constatou-se nos trabalhos a utilização de Sistemas de Mensuração de Desempenho nas atividades do controle estatístico de processos. Os resultados indicam ainda a utilização de indicadores, oriundos de modelos realistas de Avaliação de Desempenho, centrados na qualidade estatística sem ter em conta as necessidades, os valores e as preferências dos gestores dos contextos avaliados. 
Palavras- Chave: Avaliação de Desempenho, Controle estatístico, Bibliometria.

\begin{abstract}
The study aims to identify the topics addressed in the international scientific literature on the subject of Performance Assessment in Statistical Control Management Process (CEP), in order to identify opportunities for improvement. This exploratory research used ProKnow-C as an intervention tool for the selection of the bibliographic-PB portfolio and analysis of the characteristics of this fragment of literature. The prominent authors identified were Lea Pearn Wen, and Shu-Ming Chung, with 5, 4 and 3 publications in the PB respectively. It was also possible to identify the periodicals Quality and Reliability Engineering International and Expert Systems with Applications as the two periodicals with the highest number of publications. In relation to the keywords present in the portfolio, those that stood out were Process Capability Indices, Control Charts, and Process Capability index. The periodicals with greatest impact factor were: European Journal of Operational Research and Expert Systems with Applications. The works found identified the use of Performance Measurement Systems in the activities of statistical process control. The results also indicate the use of indicators, derived from realistic models of performance evaluation, focusing on statistical quality but without taking into account the managers' needs, values and preferences of the contexts evaluated.
\end{abstract}

Keywords: Performance Evaluation, Statistical Control, Bibliometrics.

\title{
RESUMEN
}

Este estudio tiene como objetivo identificar lo que la literatura científica internacional aborda sobre el tema Evaluación de Desempeño en la Gestión del Control Estadístico de Procesos (CEP), posibilitando así la identificación de oportunidades de perfeccionamiento. La investigación exploratoria utilizó como instrumento de intervención el ProKnow-C para la selección do portafolio bibliográfico-PB y el análisis de las características de este fragmento de la literatura. Los autores de destaque identificados fueron Wen Lea Pearn, Shu-Ming Chung, con 5, 4, y 3 publicaciones respectivamente en el PB. También fue posible identificar los periódicos Quality and Reliability Engineering International y el Expert Systems With Applications como los dos con mayor número de publicaciones. En relación a las palavras clave presentes en los artículos del portafolio, las que se destacaron fueron Process Capability Indices, Control Charts y Process Capability index. Los periódicos que presentaron mayor factor de impacto fueron: European Journal of Operational Research y Expert Systems with Applications. En los trabajos se observó la utilización de Sistemas de Mensuración de Desempeño en las actividades del control estadístico de procesos. Los resultados indican también la utilización de indicadores, oriundos de modelos realistas de Evaluación de Desempeño, centrados en la calidad estadística sin tener en cuenta las necesidades, los valores y las preferencias de los gestores de los contextos evaluados.

Palabras clave: Evaluación de Desempeño; Control estadístico; Bibliometría.

\section{INTRODUÇÃO}

O cenário competitivo e globalizado no qual as empresas estão inseridas tem exigido a introdução de novas formas de produção e gerenciamento dos processos por parte das organizações. Essa demanda vem ao encontro da exigência dos consumidores, que cada vez mais buscam produtos com melhor qualidade e a baixo custo. Desse modo, as empresas têm buscando adequar seus métodos de produção e de gestão particularmente no concernente às buscas por padrões de qualidade que propiciem diferenciais competitivos (DA SILVA; PEREIRA, 2009). Nesse contexto, as ferramentas do Controle Estatístico do Processo (CEP) têm se configurado como eficientes ferramentas para alcançar a qualidade nos processos (TOPALIDOU; PSARAKIS, 2009; ALREFAIE; BATA, 2010).

Nos processos contínuos e estáveis existentes nos produtos de fabricação em larga escala, os padrões de qualidade são alcançados via análise de fatores com informações completas, futuro previsível, objetivos tangíveis e não conflitantes. Neste ambiente os modelos de gestão realistas (normativistas e descretivistas) têm se consolidado como os mais apropriados (ROY, 1993). 
A gestão dos Controles Estatístico dos Processos (CEP) assume um grau de complexidade diferente quando as linhas de produção necessitam trabalhar sincronizadas com outras atividades; necessitam atender a múltiplos produtos de múltiplos clientes com importâncias diferentes e dinâmicas, informações difusas, tempo e insumos escassos, mão de obra e equipamentos limitados, e consequências financeiras e imagem afetadas pelas decisões do CEP (CELANO et al., 2011; KAYA; KAHRAMAN, 2011; HAQ; BROWN; MOLTCHANOVA, 2014).

Para a gestão de CEP, pesquisadores como Hsu e Shu (2008), Chen, Lai e Nien (2010) e Al-Refaie e Bata (2010) têm alertado para a necessidade do uso de ferramentas de avaliação de desempenho em apoio à gestão de CEP que ademais da qualidade e produtividade clássicas (visão ontológica) tenham em conta os valores e as preferências dos gestores e as particularidades dos ambientes organizacionais (visão epistemológica).

Frente a estas informações, a presente pesquisa tem como indagação central: Como conhecer os trabalhos científicos publicados sobre o tema gestão do CEP e evidenciar seus principais parâmetros?

Este trabalho está estruturado em cinco seções, tendo a primeira caráter introdutório acerca do tema da pesquisa e da apresentação dos objetivos do trabalho. A segunda apresenta a fundamentação teórica sobre avaliação de Desempenho e do objeto de investigação desse estudo: Avaliação de Desempenho na aplicação do CEP. Na terceira seção está o instrumento de pesquisa utilizado e a metodologia de pesquisa apresentada. A quarta apresenta a operacionalização do processo, bem como todas as etapas necessárias para a obtenção do PB e a Análise Bibliométrica realizada. Na quinta e última seção são relatadas as considerações finais.

\section{FUNDAMENTAÇÃO TEÓRICA}

Nesta seção são apresentados conceitos e origens da Avaliação de Desempenho Construtivista, além de evidenciar a forma com que ocorre a Avaliação de Desempenho no CEP, que servirá como parâmetro de análise avançada dos artigos do PB.

\subsection{Avaliação de Desempenho Construtivista}

Ao longo dos anos, a avaliação de desempenho e seus indicadores fazem partem do processo de evolução da humanidade, desde os primeiros registros formais de sua existência registrados no Tratactus de Computis et Scripturis do Summa de arithmetica, geometrica, proportioni et proportionalita, trabalho publicado em 1494 por Frei Luca Bartolomeo de Paccioli, descrevendo de métodos contábeis dos mercadores venezianos (ENSSLIN et al., 2015).

Com o advento da revolução industrial no século XVIII e os trabalhos de Francis Bacon (Novum Organum, 1620), o conhecimento científico se consolidou, e com isso a avaliação de desempenho começou a subsidiar os processos produtivos, em um primeiro momento no controle da qualidade, visando criar condições competitivas por meio da redução de custos dos produtos.

Seguindo esta tendência, as contribuições da avaliação de desempenho se consolidaram no século XX, com a introdução da produção em escala no meio empresarial e o estudo da administração científica no meio acadêmico. Desde as primeiras evidenciações do uso da ciência como ferramenta para apoiar as pessoas e as organizações, como proposto por Francis Bacon (1620), passando pelos princípios da Teoria da Administração no início do século XX, os modelos realistas de grande destaque em áreas como a física e a matemática até as contribuições das abordagens construtivistas das últimas décadas, como proposto por Landry (1995), Roy (1993), Keeney (1992), têm ajudado pesquisadores e gestores em suas funções profissionais e pessoais, valendo-se dos conhecimentos científicos para aperfeiçoar e inovar seus métodos e formas de agir.

Os diversos conceitos para avaliação de desempenho e as lacunas de conhecimento existentes em relação à sua vertente de apoio à decisão fizeram com que Ensslin et al. (2010, p. 130) propusessem a seguinte definição para a avaliação desempenho, como um instrumento de apoio à decisão:

Avaliação de Desempenho é o processo para construir conhecimento no decisor, a respeito do contexto específico que se propõe avaliar, a partir da percepção do próprio decisor por meio de atividades que identificam, organizam, mensuram ordinalmente e cardinalmente, integram e permitem visualizar o impacto das ações e seu gerenciamento (ENSSLIN et al., 2010, p. 130). 
Desta forma, a avaliação de desempenho é utilizada como um instrumento de gestão para construir, fixar e expandir conhecimento de formas a permitir monitorar e aperfeiçoar o contexto que o decisor deseja realizar na gestão (ENSSLIN et al., 2010).

\subsection{A Avaliação de Desempenho do Controle Estatístico de Processo - CEP}

O CEP configura-se como uma ferramenta com o propósito de facilitar a redução da variabilidade da produção e permite a verificação do percentual de produção dos produtos defeituosos, se essa se apresenta em níveis aceitáveis ou não (TOPALIPADEU; SPARAKIS, 2009). De acordo com Kaya e Kahramam (2011, p.1), "0 CEP envolve métodos que visam avaliar, monitorar e possivelmente reduzir a variabilidade nos processos de produção industrial".

Dentre estes métodos, destaca-se a utilização da carta de controle de Shewhart, que fornece informações sobre as disfunções dos processos produtivos. As amostras coletadas no processo sofrem tratamento estatístico e são plotadas nos gráficos, o qual é representado por limites de controle. Caso alguma das amostras se comportem fora dos limites, há incidência de causas especiais, desse modo devem ser adotados procedimentos para detectar a origem dessas causas, corrigindo assim o problema para que o processo volte ao estado desejável, ou seja, sob controle estatístico (TOPALIPADEU; SPARAKIS, 2009).

Sabe-se que, mesmo sob controle estatístico, um processo ainda está sujeito a produzir itens defeituosos. Destaca-se a importância da utilização dos índices de capacidade, que permitem medir se o processo é capaz de atender às especificações do cliente. Hsu e Shu (2008) evidenciam que este índice tem auxiliado as empresas a se manterem competitivas e líderes de mercado por meio da avaliação de desempenho da qualidade e da produtividade. Chen Lai e Nien (2010) descrevem que estes índices têm auxiliado os gestores das organizações a lidar com problemas complexos que envolvem, por exemplo, a mensuração do desempenho atual dos processos. A gestão do CEP nesta visão vai além do mero aceitar/rejeitar lotes de fabricação para ter em conta as múltiplas variáveis de todo o contexto envolvendo, além da qualidade e da produtividade, a definição da sequência de produção, a definição dos níveis de inspeção, os fornecedores de insumos, o cliente a quem se destina, as formas de medição; o tamanho dos lotes, dentre outras.

Para atender a esta demanda de qualidade, faz-se necessária a mensuração do desempenho dos processos, que de acordo com Melnyk et al., (2014) pode ocorrer por meio de duas maneiras: (i) Com a utilização de Sistemas de Mensuração de Desempenho, que abrangem processos de estabelecimento de metas, desenvolvem indicadores operacionais, analisando e interpretando os dados do desempenho; e (ii) Com a utilização de Sistemas de Gestão do Desempenho que convergem com a vertente de apoio à decisão, seguida neste trabalho, e tem como foco a avaliação das diferenças entre resultados obtidos e desejados, nos quais estas disfunções são analisadas a ponto de se compreender sua origem e seus impactos, gerando assim ações corretivas, que promovem o aperfeiçoamento do contexto de gestão avaliado.

\section{METODOLOGIA}

Nesta seção é apresentado o enquadramento metodológico utilizado, bem como o instrumento selecionado para a coleta e análise dos dados.

\subsection{Enquadramento Metodológico}

O objetivo de pesquisa desse trabalho pode ser classificado de natureza exploratória e descritiva. Exploratória porque apresenta um processo organizado de seleção de artigos científicos que permitem aos pesquisadores obterem conhecimento acerca do assunto, e é descritiva devido às características descritas do PB (RICHARDSON, 2008).

A abordagem de pesquisa utilizada foi a qualitativa, uma vez que buscou identificar e analisar o perfil das publicações presentes no portfólio e revelar os gaps existentes referentes ao tema de pesquisa (RICHARDSON, 2008). 0 construtivismo foi a base filosófica adotada, por permitir aos pesquisadores entender a situação e os possíveis caminhos que eles poderão seguir diante desse contexto (ROY,1993; DUTRA et al., 2015). 
Como os pesquisadores atuarão diretamente nas pesquisas, estabelecendo limitações para cada fase que compreende o processo, a estratégia de investigação adotada é a pesquisa ação. Após a primeira fase da pesquisa será realizada a fase de análise do PB para identificar as pesquisas do fragmento da literatura que compreendem a Avaliação de Desempenho na implantação do CEP.

A lógica de pesquisa adotada é a indutiva, por se tratar de um problema inexplorado e que possibilitará a obtenção do conhecimento a partir dos dados coletados e das observações realizadas (CRESWELL, 2010). Na coleta dos dados utilizam-se dados primários e secundários. Os dados primários são coletados na fase de seleção do PB, cujos pesquisadores atuam diretamente nas pesquisas, coletando e selecionando os artigos científicos; já os dados secundários compreendem a fase de análise das características identificadas nos artigos do PB.

Uma vez que a presente pesquisa se utiliza do conhecimento advindo de artigos científicos, ela pode ser classificada também como bibliográfica. $O$ instrumento de intervenção adotado para que os objetivos do presente trabalho sejam alcançados será o Knowledge Development Process-Constructivist (Proknow) a partir da visão construtivista (TASCA et al., 2010; ENSSLIN, L.; ENSSLIN, S.; PINTO, 2013; DUTRA et al., 2015).

\subsection{Instrumento de Intervenção}

Desenvolvido por pesquisadores do LabMCDA da Universidade Federal de Santa Catarina (UFSC), o ProKnow- $C$ configurou-se como uma importante e eficiente ferramenta que objetiva a seleção e a análise do PB referente ao fragmento da literatura (assunto) na qual o pesquisador escolhe para construir conhecimento para si próprio e também para a comunidade científica.

Nos últimos anos, diversos trabalhos vêm sendo publicados (TASCA et al., 2010; LACERDA; ENSSLIN; ENSSLIN, 2012; ENSSLIN, L.; ENSSLIN, S.; PINTO, 2013; DA ROSA et al., 2015; DUTRA et al., 2015; ENSSLIN et al., 2015;) em diferentes áreas de conhecimento, estes estudos fazem uso do ProKnow-C para: (i) Identificar um fragmento da literatura relevante sobre o tema de interesse do pesquisador (Portfólio Bibliográfico); (ii) Conhecer as peculiaridades da área de estudo; (iii) Realizar análise crítica deste PB a partir da corrente teórica selecionada pelo pesquisador; e (iv) Sugerir lacunas na literatura que subsidiem a formulação de futuros trabalhos. Para entendimento do leitor, é apresentado a Figura $1 \mathrm{com}$ as quatro etapas que compreendem o processo de operacionalização do ProKnow-C:

Figura 1: Macroprocesso do ProKnow-C

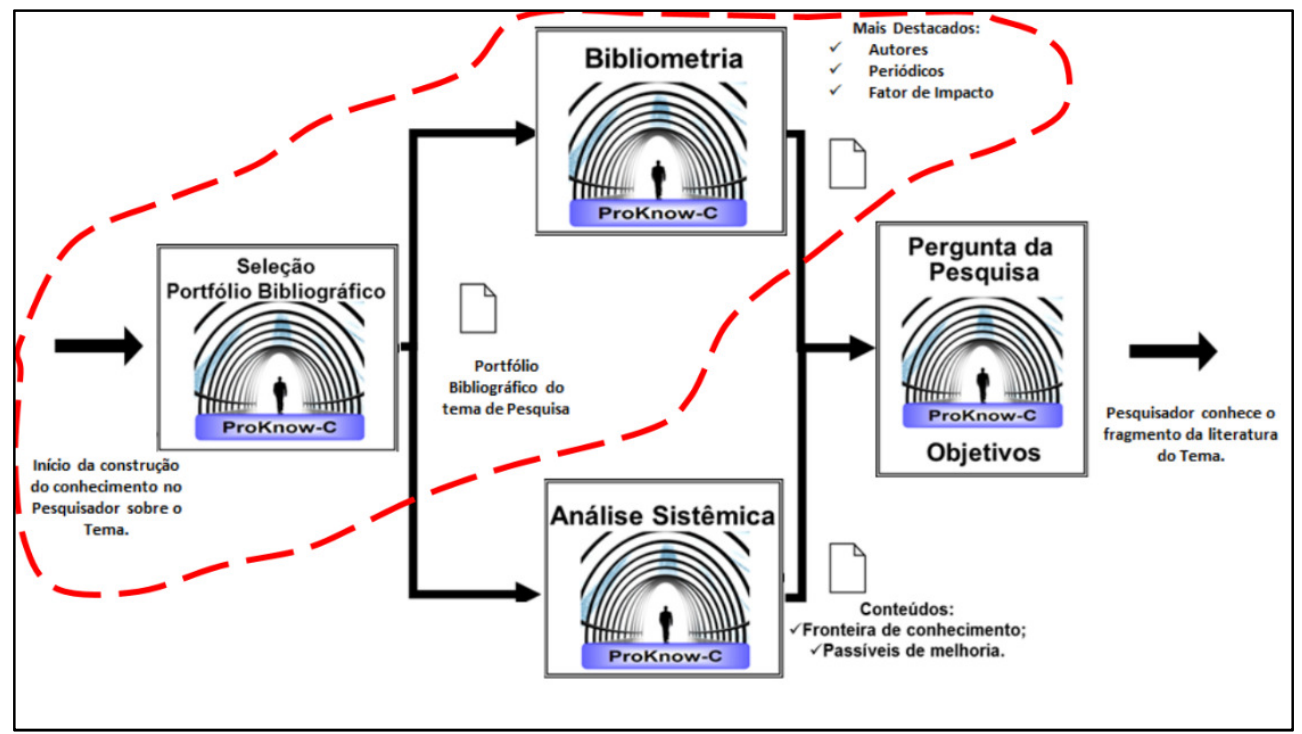

Fonte: Adaptado de Tasca et al. (2010).

Como pode ser observado pelas etapas destacadas na Figura 1, apenas a Seleção do PB e a Bibliometria foram utilizadas para a presente pesquisa, as quais serão detalhadas na seção Procedimentos para Coleta de Dados e nos Resultados da Bibliometria. 


\subsubsection{Procedimentos para Coleta de Dados}

A aplicação do processo ProKnow-C abrange a seleção de um portfólio bibliográfico- PB relevante e alinhado ao tema pesquisado e, a partir deste, a realização de sua análise bibliométrica. Para a seleção do $\mathrm{PB}, 0$ ProKnow-C inicia com a definição da composição do tema. Esta composição é realizada pela especificação dos assuntos que, no entender dos pesquisadores, explicam em forma exaustiva o tema a ser pesquisado. A estes assuntos o ProKnow-C chama de eixos. Para a presente pesquisa, o tema é gestão de CEP e os eixos utilizados são: Avaliação de Desempenho; Organizações e CEP. A seguir, o ProKnow-C requer que, para cada eixo, sejam definidas suas palavras-chave e a combinação das mesmas para o processo de busca. A etapa seguinte é a de definir as bases de dados onde será realizada a busca, seguindo-se a busca propriamente dita.

A pesquisa foi realizada no mês de outubro de 2015, com as seguintes delimitações: (i) bases de dados: ISIS WEB of Science e Scopus; (ii) temporal: entre 2005 e 2015; (iii) apenas artigos publicados em periódicos científicos; (iv) idioma: artigos exclusivamente em língua inglesa. A Figura 2 apresenta a operacionalização dessa etapa e a coleta dos dados.

Figura 2: Operacionalização do Proknow- C.

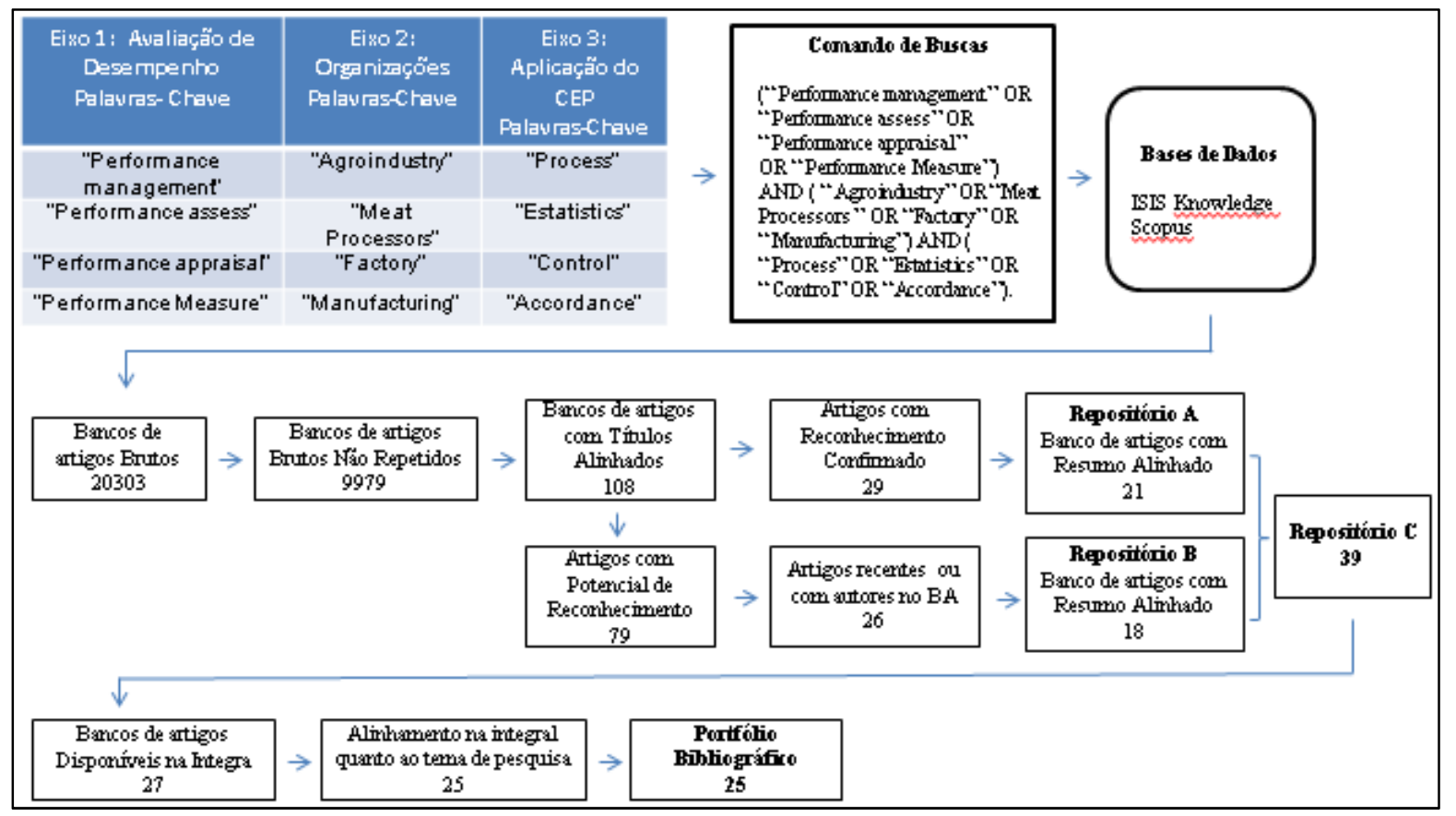

Fonte: Elaborada pelos autores (2016).

Na seleção dos artigos brutos, foram encontrados 20.303 artigos. Essas publicações foram exportadas para o software EndNote e 10.324 destes foram excluídos por serem repetidos, devido à utilização de duas bases de pesquisas diferentes. Em seguida, fez-se a leitura dos títulos para verificar o alinhamento destes com o tema da pesquisa, assim mais 9.871 artigos foram excluídos, restando nessa etapa 108 publicações.

A próxima etapa da pesquisa compreendeu avaliar os artigos quanto ao seu reconhecimento científico. Compreendendo $80 \%$ das citações, 29 artigos foram selecionados para a leitura do seu resumo, destes 8 foram eliminados, restando assim 21 publicações no repositório $A$.

Na sequência, foram realizados as novas filtragens e os testes de representatividade com os 79 artigos restantes do banco de artigos brutos, os quais ainda não possuíam reconhecimento científico confirmado. Destes, 18 artigos foram reconsiderados devido a datas respectivas de publicação (menos de 2 anos), mais 8 deles pela presença de seus autores no banco do repositório A. Dessas 26 publicações, 18 foram consideradas com o resumo alinhado, representando assim o Repositório $B$.

Ao fundir os dois repositórios ( $\mathrm{A}$ e $\mathrm{B}$ ), obteve-se um novo banco, denominado nesse estudo como repositório $\mathrm{C}$, contendo 39 artigos. Ao verificar sua disponibilidade na íntegra, constatou-se que apenas 27 
encontravam-se disponíveis. A próxima e última etapa constituiu-se em ler o artigo na íntegra e verificar seu alinhamento com o tema de pesquisa. Desta forma, dois artigos foram desconsiderados, consolidando assim um PB composto por 25 artigos científicos.

\subsubsection{Procedimentos para análise de dados}

Após a seleção do PB, é colocada em prática a segunda etapa do Proknow-C (Bibliometria), que compreende a análise e a interpretação dos dados obtidos por meio dos 25 artigos.

A análise Bibliométrica desenvolvida neste trabalho visa gerar conhecimento aos pesquisadores acerca das características que envolvem as publicações contidas no PB, bem como saber como e qual caminho adotar para encontrar informações pertinentes ao tema (DUTRA et al., 2015; ENSSLIN et al., 2015).

\section{RESULTADOS}

Nesta seção são apresentados os resultados das análises realizadas de acordo com as características do PB. As seguintes características foram avaliadas: (i) autores de destaque na área de conhecimento; (ii) os periódicos científicos que têm contribuído com a divulgação das pesquisas; (iii) palavras-chave mais utilizadas; (iv) Análise avançada do Portfólio Bibliográfico.

\subsection{Autores de destaque no PB e nas referências bibliográficas}

$\mathrm{Na}$ análise do PB, foi possível identificar 50 autores, destes 8 apresentam mais que uma publicação no PB. Os autores com maior participação em publicações são: Wen Lea Pearn, PhD, Professor na University of Maryland, com 5 publicações de periódicos; Shu-Ming Chung, PhD, Professor na The University of Tokyo, com 4 publicações; e Bi-Min Hsu, do Departament of Industrial Engineering and Management of University Taiwan, com 3 periódicos. A Figura 3 apresenta a quantidade de publicações dos autores.

Figura 3: Autores de destaque no PB

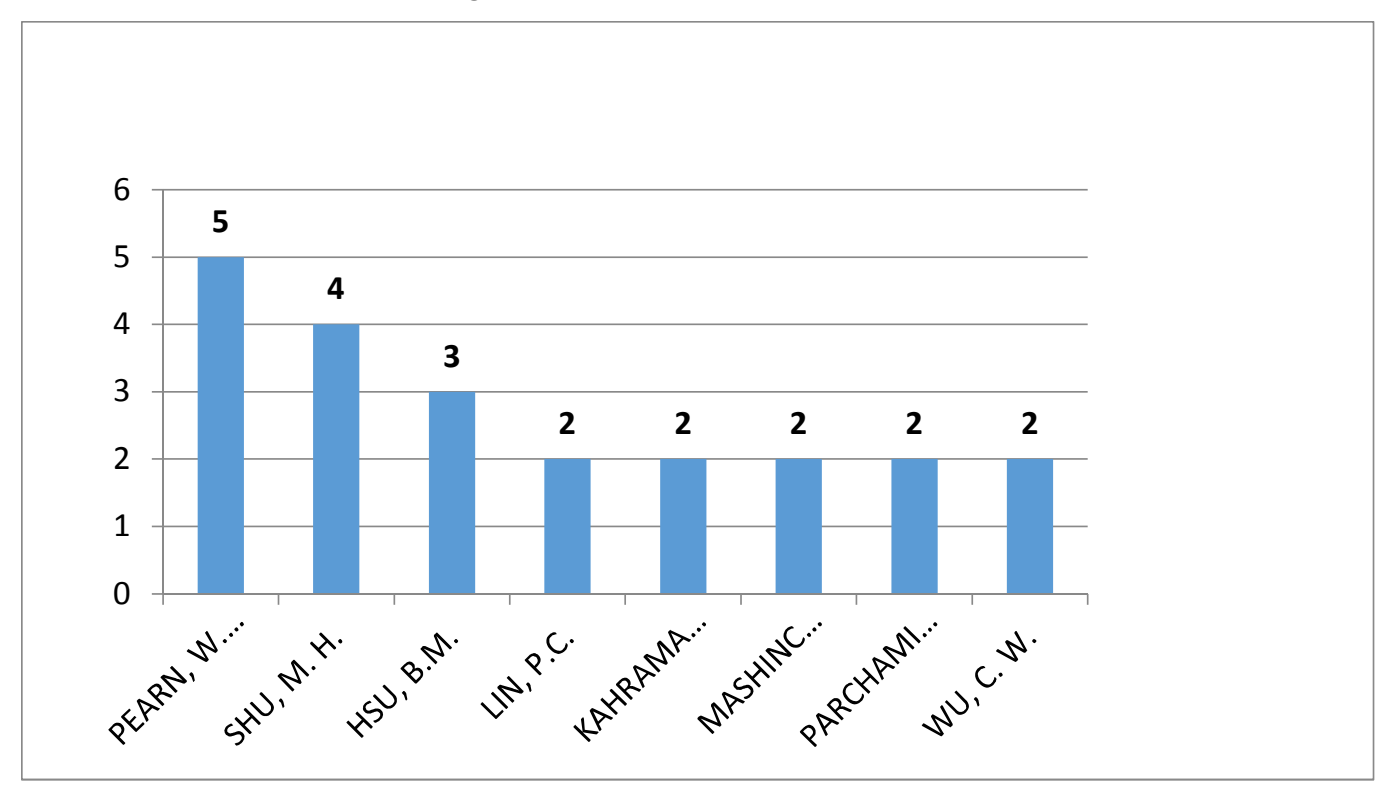

Fonte: Elaborada pelos autores (2016).

Análise similar foi realizada nas referências do PB, onde se observou que Wen Lea Pearn e Kahraman são os destaques, seguidos de Kaya, I. e Kotz, S. A Figura 4 apresenta a quantidade de publicações por autor constantes das referências bibliográficas do PB. 
Figura 4: Autores de destaque nas referências do PB

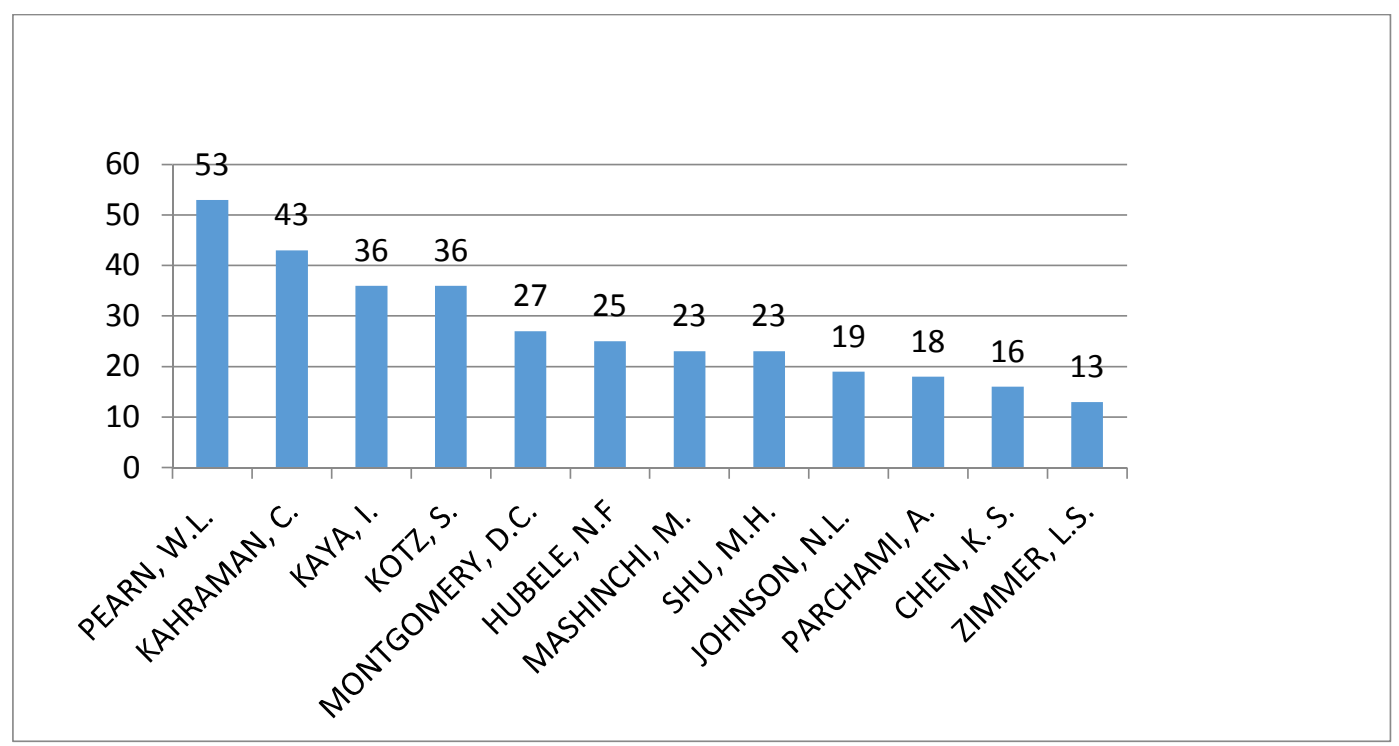

Fonte: Elaborada pelos autores (2016).

\subsection{Periódicos científicos relevantes no PB e nas referências do PB}

Dentre os 16 periódicos identificados no PB, Quality and Reliability Engineering International apresentou o maior número de publicações, nove no total, seguido da Expert Systems With Applications com duas. Os demais periódicos apresentaram somente uma publicação, como pode ser observado na Figura 5, que apresenta o número de artigos por periódico.

Figura 5: Periódicos relevantes do PB.

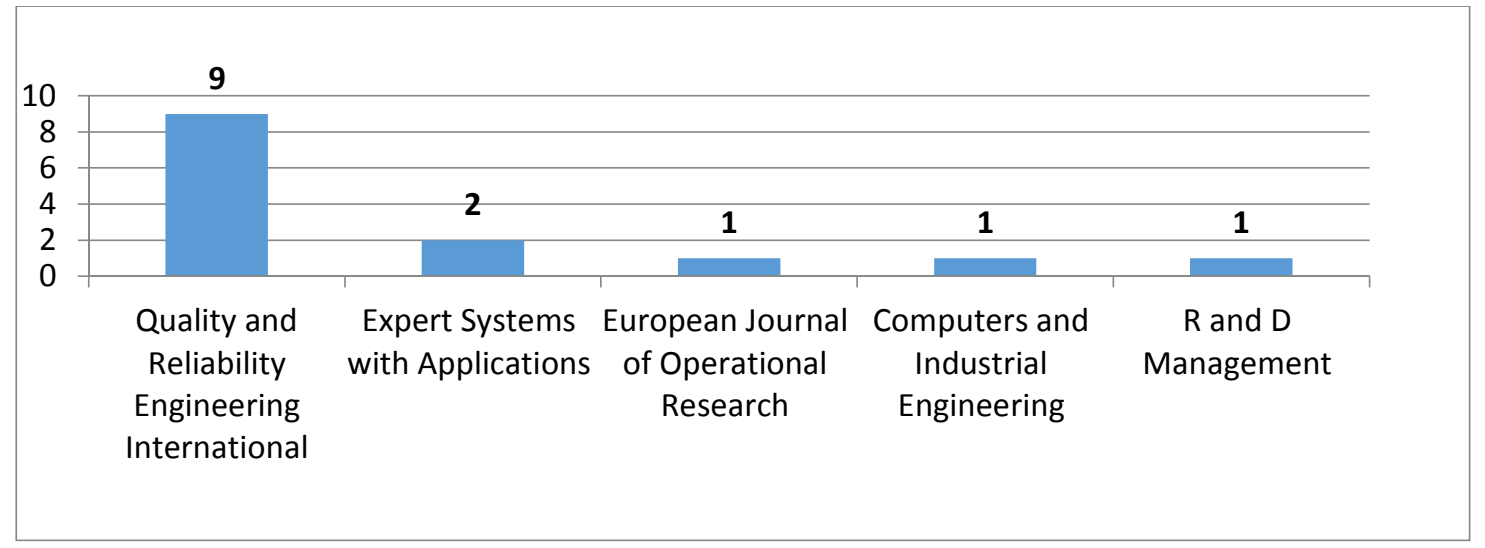

Fonte: Elaborada pelos autores (2016).

A análise dos periódicos relevantes das referências bibliográficas do PB se deu por meio da identificação de todas as referências bibliográficas contidas nos artigos científicos pertencentes ao portfólio. O periódico Quality and Realiability Engineering configurou-se novamente como o periódico mais relevante, contendo 74 publicações, seguido pelo Jornal of Quality Tecnology, com 69, e pelo International Journal of Production Research, com 38. A Figura 6 apresenta o número de artigos por periódico. 
Figura 6: Periódicos Relevantes das Referências

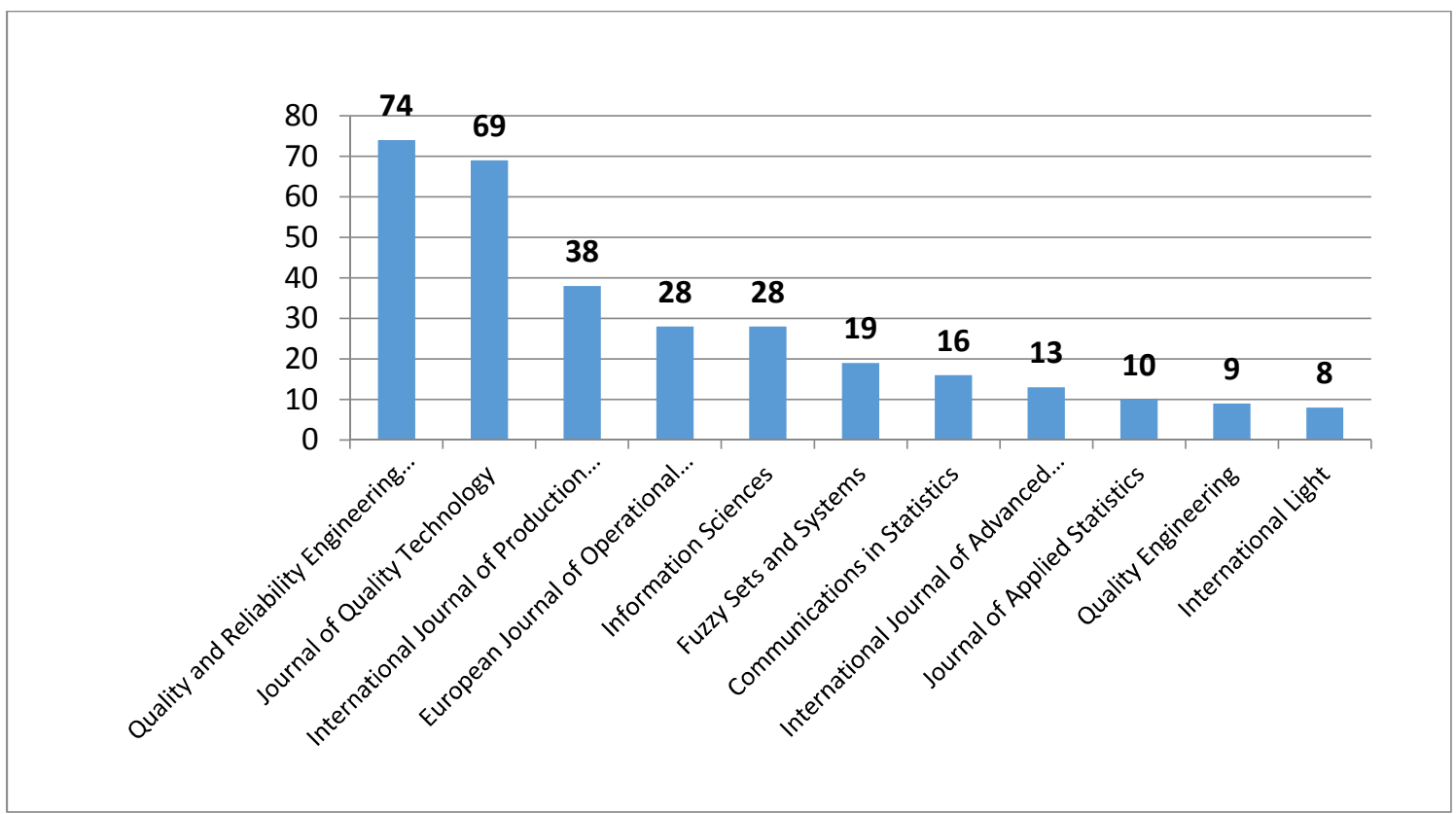

Fonte: Elaborada pelos autores (2016).

Outra característica importante na análise do PB são as palavras-chave utilizadas pelos autores; devido à sua função de identificar e caracterizar um trabalho científico, o conhecimento dessas palavras possibilita aos pesquisadores obterem resultados consistentes nos levantamentos. A Figura 7 apresenta as palavras-chave utilizadas no PB.

\subsection{Palavras-Chaves do PB}

As palavras-chave relevantes identificadas no PB foram: Process Capability Indices, em nove publicações; Control Carts, com seis; e Process Capability index, apresentando cinco publicações. A Figura 7 apresenta as demais palavras de destaque:

Figura 7: Palavras-chave de destaque nos artigos do PB

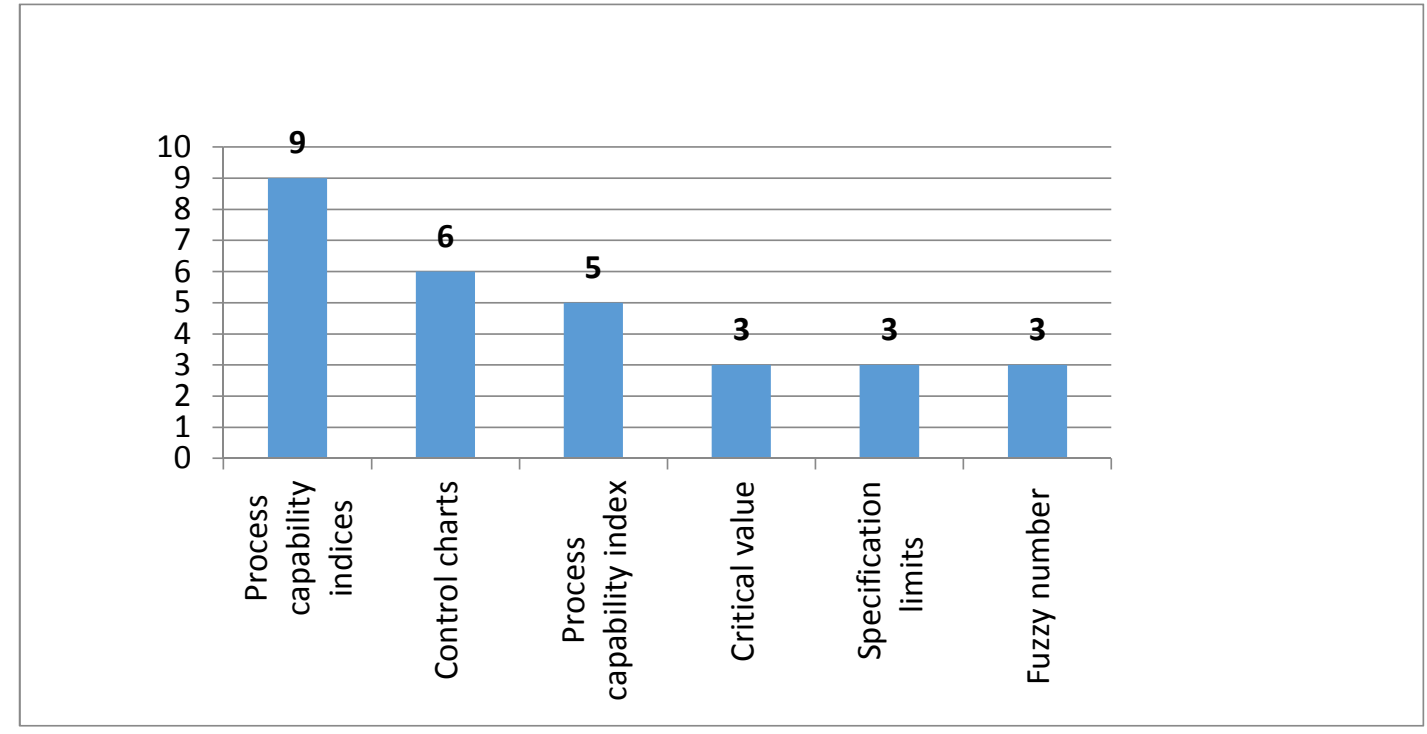

Fonte: Elaborada pelos autores (2016). 
A partir deste conhecimento, percebe-se que as palavras-chave definidas nos eixos de pesquisa deste trabalho indicam o estudo de indicadores de desempenho, que podem mensurar fatores inerentes à qualidade $e$ ao CEP.

\subsection{Fator de impacto dos periódicos}

A avaliação quanto aos fatores de impactos dos periódicos leva em consideração o número de citações dos artigos nos dois últimos anos que antecedem à consulta e ao número de artigos publicados no período. À medida que o número de citações for maior do que as publicações, maior será o valor de impacto e vice-versa. No presente estudo, as bases de pesquisas as quais possibilitaram as consultam foram as bases ISI Web of Knowledge (JCR) e Scopus (SJR). A Figura 8 ilustra os resultados da consulta.

Figura 8: Fator de impacto dos periódicos

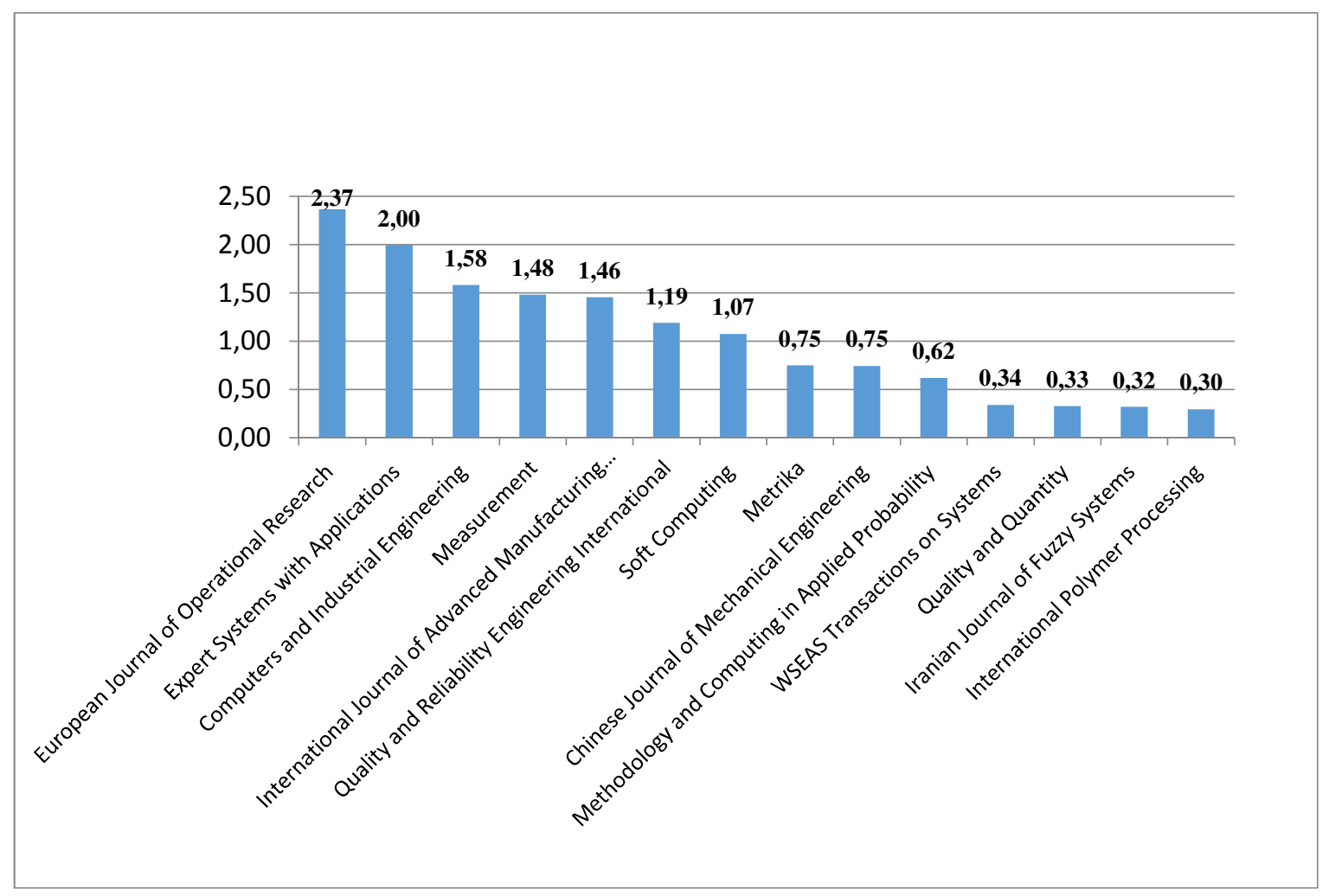

Fonte: Elaborada pelos autores (2016).

Como pode ser verificado, os periódicos que possuem maior fator de impacto são European Jounal of Operational Research (2,37); Expert Systems with Applications (2,00); Computers and Industrial Engeering $(1,58)$; Measurament (1,48); International Journal of Advanced Manufacturing Technology $(1,46) ;$ Quality and Reliability Engineering International $(1,19)$; e Soft Computing $(1,07)$. Os demais periódicos apresentaram fator de impacto inferior a um, o que significa que o número de publicações deles foi maior que o número de citações no mesmo período.

\subsection{Análises avançadas do Portfólio Bibliográfico}

Esta seção apresenta a análise dos artigos do PB em relação à: (i) Classificação de acordo com o conceito de avaliação de desempenho proposto por Melnyk et al. (2014); (ii) Identificação do modelo utilizado para medir o desempenho; e (iii) Análise dos resultados obtidos com os trabalhos. A Figura 9 apresenta os resultados obtidos por meio da classificação. 
Quadro 1: Classificação quanto as variáveis avançadas

\begin{tabular}{|c|c|c|c|}
\hline Artigo & $\begin{array}{c}\text { Classificação do } \\
\text { Sistema de Avaliação } \\
\text { de Desempenho } \\
\text { (MELNYK et al., 2014) }\end{array}$ & $\begin{array}{c}\text { Modelo Utilizado para medir } \\
\text { o desempenho }\end{array}$ & Resultados \\
\hline $\begin{array}{l}\text { Process capability } \\
\text { analyses based on fuzzy } \\
\text { measurements and fuzzy } \\
\text { control charts (KAYA; } \\
\text { KAHRAMAN, 2011). }\end{array}$ & $\begin{array}{l}\text { Sistema de Medição de } \\
\text { desempenho }\end{array}$ & $\begin{array}{l}\text { Índices de Controle de } \\
\text { Processo (PCls) foram obtidos } \\
\text { para medições difusas que } \\
\text { foram definidas por valores } \\
\text { linguísticos ou aproximados. } \\
\text { Para verificar a existência de } \\
\text { controle estatístico, gráficos de } \\
\text { controle complexos foram } \\
\text { produzidos e, em seguida, } \\
\text { difusos PCls foram derivados. }\end{array}$ & $\begin{array}{l}\text { Por meio dos resultados } \\
\text { obtidos, constatou-se que } \\
\text { PCls distorcidos incluem } \\
\text { valores nítidos com um valor } \\
\text { de adesão de } 1,00 \text { e mostram } \\
\text { todos os valores possíveis } \\
\text { dos PIC, o que os tornam } \\
\text { mais úteis do que utilizar } \\
\text { apenas um único resultado. } \\
\text { Os gráficos de controle } \\
\text { também foram eficientemente } \\
\text { aplicados determinando todas } \\
\text { as causas atribuíveis. } \\
\text { A utilização do conjunto fuzzy } \\
\text { proporcionou informações e } \\
\text { uma maior flexibilidade, } \\
\text { permitindo assim um ponto de } \\
\text { vista mais amplo acerca da } \\
\text { média do processo e sua } \\
\text { variância. }\end{array}$ \\
\hline $\begin{array}{l}\text { A New Cumulative Sum } \\
\text { Quality Control Scheme } \\
\text { for Monitoring the Process } \\
\text { Mean (HAQ; BROWN; } \\
\text { MOLTCHANOVA, 2014). }\end{array}$ & $\begin{array}{c}\text { Sistema de Medição de } \\
\text { desempenho }\end{array}$ & $\begin{array}{l}\text { Foram realizadas simulações } \\
\text { para estimar o comprimento } \\
\text { médio, e o desvio padrão de } \\
\text { comprimento de percurso. Os } \\
\text { gráficos CUSUM foram então } \\
\text { comparados a outros gráficos } \\
\text { de controle existentes } \\
\text { propostos por diversos } \\
\text { pesquisadores. }\end{array}$ & $\begin{array}{l}\text { Os resultados apresentados } \\
\text { indicam que o modelo } \\
\text { utilizado é capaz de realizar o } \\
\text { controle de qualidade de } \\
\text { maneira mais uniforme do } \\
\text { que as cartas de controle } \\
\text { CUSUM, FIR-CUSUM, } \\
\text { ACUSUM-C, AEWMA e } \\
\text { SHEWHART-CUSUM } \\
\text { especialmente por detectar } \\
\text { mudanças aleatórias na } \\
\text { média do processo, a } \\
\text { utilização do sistema de } \\
\text { controle proposto é } \\
\text { recomendada pelo autor do } \\
\text { presente trabalho. }\end{array}$ \\
\hline $\begin{array}{l}\text { Measuring process } \\
\text { capability index C pm with } \\
\text { fuzzy data (CHEN; LAl; } \\
\text { NIEN, 2010). }\end{array}$ & $\begin{array}{c}\text { Sistema de Medição de } \\
\text { desempenho }\end{array}$ & $\begin{array}{l}\text { Neste trabalho os a-cortes de } \\
\text { observações fuzzy são } \\
\text { derivados com base em } \\
\text { diferentes valores de a. A } \\
\text { função de pertinência da } \\
\text { capacidade do processo } \\
\text { distorcida em índice CPM é } \\
\text { então calculada com base nos } \\
\text { a-cortes de observações } \\
\text { difusas. }\end{array}$ & $\begin{array}{l}\text { Os métodos propostos } \\
\text { reduzem a fórmula clássica } \\
\text { para o cálculo do índice de } \\
\text { capacidade CPM. } \\
\text { O índice de capacidade } \\
\text { expresso em números fuzzy é } \\
\text { mais informativo do que o } \\
\text { apresentado em números } \\
\text { nítidos. O método proposto } \\
\text { neste trabalho é apropriado } \\
\text { para a tomada de decisão } \\
\text { quando as características de } \\
\text { qualidade não podem ser } \\
\text { determinadas com precisão. }\end{array}$ \\
\hline
\end{tabular}

(Continuação...) 
(Continuação...)

\begin{tabular}{|c|c|c|c|}
\hline Artigo & $\begin{array}{c}\text { Classificação do } \\
\text { Sistema de Avaliação } \\
\text { de Desempenho } \\
\text { (MELNYK et al., 2014) }\end{array}$ & $\begin{array}{c}\text { Modelo Utilizado para medir } \\
\text { o desempenho }\end{array}$ & Resultados \\
\hline $\begin{array}{l}\text { Shewhart and EWMA } t \\
\text { Control Charts for Short } \\
\text { Production } \quad \text { Runs } \\
\text { (CELANO et al., 2011). }\end{array}$ & $\begin{array}{c}\text { Sistema de Medição de } \\
\text { desempenho }\end{array}$ & $\begin{array}{l}\text { Foram calculadas medidas } \\
\text { estatísticas de desempenho } \\
\text { para avaliar a sensibilidade dos } \\
\text { indicadores a curto prazo, } \\
\text { levando em conta a hipótese de } \\
\text { uma configuração de um } \\
\text { processo perfeito inicial e um } \\
\text { erro de configuração. }\end{array}$ & $\begin{array}{l}\text { Os resultados obtidos a partir } \\
\text { dos testes revelam que o } \\
\text { modelo é capaz de detectar } \\
\text { rapidamente a ocorrência de } \\
\text { uma condição fora de } \\
\text { controle; além disso, é pouco } \\
\text { influenciado pelo ruído } \\
\text { introduzido e pela mudança } \\
\text { inesperada na dispersão do } \\
\text { processo. }\end{array}$ \\
\hline $\begin{array}{lr}\text { Modified } & \text { Multivariate } \\
\text { Process } & \text { Capability Index } \\
\text { Using } & \text { Principal } \\
\text { Component } & \text { Analysis } \\
\text { (ZHANG et al., 2014) }\end{array}$ & $\begin{array}{c}\text { Sistema de Medição de } \\
\text { desempenho }\end{array}$ & $\begin{array}{l}\text { Para demonstrar a eficácia do } \\
\text { método proposto, um conjunto } \\
\text { de dados reais de produção e } \\
\text { um conjunto de dados sintéticos } \\
\text { são usados. } \\
\text { Um procedimento de aplicação } \\
\text { também é fornecido para os } \\
\text { engenheiros de qualidade para } \\
\text { aplicara abordagem MPCl em } \\
\text { seus processos de fabricação. }\end{array}$ & $\begin{array}{l}\text { Por meio dos estudos foi } \\
\text { possível identificar a } \\
\text { viabilidade e a eficácia desse } \\
\text { novo tipo de } \mathrm{MPCl} \text {, que é } \\
\text { mais fácil de ser usado na } \\
\text { prática de produção. Sua } \\
\text { aplicação possibilitou a } \\
\text { resolução do problema } \\
\text { encontrado nos trabalhos de } \\
\text { Shinde. } \\
\text { A análise de um conjunto de } \\
\text { dados reais de produção e de } \\
\text { um conjunto de dados } \\
\text { sintético demonstra a eficácia } \\
\text { do método proposto. }\end{array}$ \\
\hline $\begin{array}{l}\text { Fuzzy Rules For Fuzzy } x \\
\text { And } R \text { Control Charts } \\
\text { (KHADEMl; AMIRZADEH, } \\
\text { 2014) }\end{array}$ & $\begin{array}{c}\text { Sistema de Medição de } \\
\text { desempenho }\end{array}$ & $\begin{array}{l}\text { A partir de uma revisão da } \\
\text { literatura foram utilizadas cartas } \\
\text { de controle e a metodologia } \\
\text { fuzzy }\end{array}$ & $\begin{array}{l}\text { Os resultados indicam que a } \\
\text { precisão das cartas de } \\
\text { controle foi elevada, } \\
\text { melhorando a eficiência dos } \\
\text { processos. }\end{array}$ \\
\hline $\begin{array}{l}\text { Yield-Based Capability } \\
\text { Index for Evaluating the } \\
\text { Performance of } \\
\text { Multivariate Manufacturing } \\
\text { Process (GU et al., 2015) }\end{array}$ & $\begin{array}{c}\text { Sistema de Medição de } \\
\text { desempenho }\end{array}$ & $\begin{array}{l}\text { Utilizando os pressupostos seis } \\
\text { sigmas e um tendência } \\
\text { estratégica, os autores } \\
\text { propõem um novo índice de } \\
\text { avaliação dos processos. }\end{array}$ & $\begin{array}{l}\text { Foi possível comprovar que a } \\
\text { variância dos processos afeta } \\
\text { o desempenho global e que o } \\
\text { índice de avaliação proposto } \\
\text { deve ser replicado em outras } \\
\text { realidades. }\end{array}$ \\
\hline $\begin{array}{l}\text { The process capability } \\
\text { analysis - } A \text { tool for } \\
\text { process performance } \\
\text { measures and metrics - } A \\
\text { case study (WOOLURU; } \\
\text { SWAM; NAGESH, 2014) }\end{array}$ & $\begin{array}{c}\text { Sistema de Medição de } \\
\text { desempenho }\end{array}$ & $\begin{array}{l}\text { Foram utilizadas } \\
\text { ferramentas de análise de } \\
\text { Capacidade de Processo, por } \\
\text { meio dos índices Cpk, Com e } \\
\text { Cpmk. }\end{array}$ & 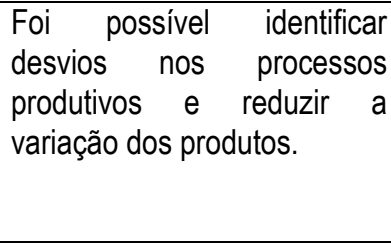 \\
\hline $\begin{array}{l}\text { Capability performance } \\
\text { analysis for processes } \\
\text { with multiple } \\
\text { characteristics using } \\
\text { accuracy and precision } \\
\text { (CHANG; WANG; CHEN, } \\
\text { 2014) }\end{array}$ & $\begin{array}{c}\text { Sistema de Medição de } \\
\text { desempenho }\end{array}$ & $\begin{array}{l}\text { A metodologia adota foi a carta } \\
\text { de controle MCPCA }\end{array}$ & $\begin{array}{l}\text { Com a utilização da } \\
\text { ferramenta é possível } \\
\text { acompanhar o desempenho } \\
\text { de processos variados de } \\
\text { maneira integrada. }\end{array}$ \\
\hline
\end{tabular}


(Continuação...)

\begin{tabular}{|c|c|c|c|}
\hline Artigo & $\begin{array}{l}\text { Classificação do } \\
\text { Sistema de Avaliação } \\
\text { de Desempenho } \\
\text { (MELNYK et al., 2014) }\end{array}$ & $\begin{array}{c}\text { Modelo Utilizado para medir } \\
\text { o desempenho }\end{array}$ & Resultados \\
\hline $\begin{array}{l}\text { Confidence interval for } \\
\text { fuzzy process capability } \\
\text { index. Sweats } \\
\text { transactions on systems } \\
\text { (PARCHAMI; } \\
\text { MASHINCHI; MALEKI, } \\
\text { 2005) }\end{array}$ & $\begin{array}{c}\text { Sistema de Medição de } \\
\text { desempenho }\end{array}$ & $\begin{array}{l}\text { A partir de um intervalo de } \\
\text { confiança para aplicação do } \\
\text { modelo fuzzy foi possível gerar } \\
\text { novas cartas de controle }\end{array}$ & $\begin{array}{l}\text { Foi possível identificar a } \\
\text { capacidade dos processos } \\
\text { por meio da teoria fuzzy, } \\
\text { estimando o intervalo de } \\
\text { confiança a partir de } 100 \text { (1- } \\
\text { a)\%. }\end{array}$ \\
\hline $\begin{array}{l}\text { Manufacturing process } \\
\text { performance evaluation } \\
\text { for fuzzy data based on } \\
\text { loss-based capability } \\
\text { index (SHU; HU, 2012) }\end{array}$ & $\begin{array}{c}\text { Sistema de Medição de } \\
\text { desempenho }\end{array}$ & $\begin{array}{l}\text { O estudo utilizou o modelo de } \\
\text { conjuntos fuzzy }\end{array}$ & $\begin{array}{l}\text { Utilizando dados aleatórios } \\
\text { com finalidade acadêmica, foi } \\
\text { possível tratar dados } \\
\text { distorcidos com certa } \\
\text { precisão; os autores sugerem } \\
\text { que em futuras pesquisas } \\
\text { sejam adotados dados de } \\
\text { empresas reais, a fim de } \\
\text { identificar o desempenho da } \\
\text { ferramenta. }\end{array}$ \\
\hline $\begin{array}{l}\text { Testing manufacturing } \\
\text { performance based on } \\
\text { capability index Com (LIN; } \\
\text { PEARN, 2005) }\end{array}$ & $\begin{array}{c}\text { Sistema de Medição de } \\
\text { desempenho }\end{array}$ & $\begin{array}{l}\text { A metodologia empregada } \\
\text { envolve a utilização do } \\
\text { indicador CPM para calcular os } \\
\text { valores de variação. }\end{array}$ & $\begin{array}{l}\text { Os autores apresentam uma } \\
\text { espécie de tutorial para } \\
\text { conduzir este tipo de teste, } \\
\text { tendo em vista que as } \\
\text { decisões tomadas com } \\
\text { análise nos indicadores } \\
\text { utilizados tendem a ser mais } \\
\text { assertivas. }\end{array}$ \\
\hline $\begin{array}{c}\text { On Average Run Lengths } \\
\text { of Control Charts for } \\
\text { Autocorrelated } \\
\text { Processes." Methodology } \\
\text { and Computing in Applied } \\
\text { Probability (CHANG; WU, } \\
\text { 2011) }\end{array}$ & $\begin{array}{c}\text { Sistema de Medição de } \\
\text { desempenho }\end{array}$ & $\begin{array}{l}\text { Incluindo gráficos de controle } \\
\text { Shewhart, gráficos CUSUM e } \\
\text { EWMA por um FMCl unificada. }\end{array}$ & $\begin{array}{llr}\text { Com } 0 & \text { uso de } & \text { uma } \\
\text { abordagem unificada para } \\
\text { estudar o tamanho de } \\
\text { percurso } \\
\text { propriedades para vários } \\
\text { gráficos, o método pode ser } \\
\text { aplicado para apresentar } \\
\text { processos instáveis. }\end{array}$ \\
\hline $\begin{array}{l}\text { Multivariate no normal } \\
\text { process capability } \\
\text { analysis (AHMAD et al., } \\
\text { 2009) }\end{array}$ & $\begin{array}{c}\text { Sistema de Medição de } \\
\text { desempenho }\end{array}$ & $\begin{array}{l}\text { O trabalho utilizou a abordagem } \\
\mathrm{CD} \text {, dada com base no conceito } \\
\text { de reduzir as dimensões } \\
\text { multivariadas, transformando } \\
\text { dados em variáveis } \\
\text { correlacionadas por meio uma } \\
\text { função de métrica. }\end{array}$ & $\begin{array}{l}\text { Esta abordagem produz uma } \\
\text { melhoria significativa a } \\
\text { mais de um método existente; } \\
\text { usando o conjunto de dados } \\
\text { escolhido, recomenda-se o } \\
\text { método proposto para ser } \\
\text { aplicado para estudos e } \\
\text { comparações. }\end{array}$ \\
\hline $\begin{array}{l}\text { Measuring process } \\
\text { capability based on Cpmk } \\
\text { with gauge measurement } \\
\text { errors (HSU; SHU; } \\
\text { PEARN, 2007) }\end{array}$ & $\begin{array}{c}\text { Sistema de Medição de } \\
\text { desempenho }\end{array}$ & $\begin{array}{l}\text { Uma simulação intensiva foi } \\
\text { utilizado para comparar o } \\
\text { desempenho do nível de } \\
\text { confiança alcançado e os } \\
\text { comprimentos intervalo médio } \\
\text { de ambas as abordagens }\end{array}$ & $\begin{array}{l}\text { O indicador avaliado } \\
\text { apresenta problemas na } \\
\text { mensuração dos processos, } \\
\text { os autores sugerem a adoção } \\
\text { de três indicadores mais } \\
\text { precisos. }\end{array}$ \\
\hline $\begin{array}{l}\text { Capability testing based } \\
\text { on Cpm with multiple } \\
\text { samples (WU; PEARN, } \\
\text { 2005) }\end{array}$ & $\begin{array}{c}\text { Sistema de Medição de } \\
\text { desempenho }\end{array}$ & $\begin{array}{l}\text { Metodologia Bayesiana para } \\
\text { avaliar os indices de } \\
\text { capacidade dos processos. }\end{array}$ & $\begin{array}{l}\text { O procedimento Bayesiano é } \\
\text { indicado para determinar se } \\
\text { os processos de fabricação } \\
\text { são capazes de reproduzir } \\
\text { produtos que satisfaçam aos } \\
\text { requisitos de precisão } \\
\text { preestabelecidos. }\end{array}$ \\
\hline
\end{tabular}


(Continuação...)

\begin{tabular}{|c|c|c|c|}
\hline Artigo & $\begin{array}{c}\text { Classificação do } \\
\text { Sistema de Avaliação } \\
\text { de Desempenho } \\
\text { (MELNYK et al., 2014) }\end{array}$ & $\begin{array}{c}\text { Modelo Utilizado para medir } \\
\text { o desempenho }\end{array}$ & Resultados \\
\hline $\begin{array}{l}\text { Evaluating measurement } \\
\text { and process capabilities } \\
\text { by GR\&R with four quality } \\
\text { measures (AL-REFAIE; } \\
\text { BATA, 2010) }\end{array}$ & $\begin{array}{c}\text { Sistema de Medição de } \\
\text { desempenho }\end{array}$ & $\begin{array}{l}\text { Foram utilizados experimentos } \\
\text { (GR \& R) projetados com quatro } \\
\text { medidas de qualidade. }\end{array}$ & $\begin{array}{l}\text { O procedimento proposto } \\
\text { nesta pesquisa utilizando GR } \\
\text { e R fornece procedimento de } \\
\text { experiências e orientações } \\
\text { úteis para a qualidade e } \\
\text { produção, possibilitando que } \\
\text { gestores tenham sistema de } \\
\text { medição e processo de } \\
\text { fabricação. }\end{array}$ \\
\hline $\begin{array}{l}\text { New capability indices for } \\
\text { evaluating the } \\
\text { performance of } \\
\text { multivariate manufacturing } \\
\text { processes (PANA; LEE, } \\
2010) \\
\end{array}$ & $\begin{array}{c}\text { Sistema de Medição de } \\
\text { desempenho }\end{array}$ & $\begin{array}{lr}\text { Correlação } & \text { entre } \\
\text { várias características } & \text { de } \\
\text { qualidade. } & \end{array}$ & $\begin{array}{l}\text { Os resultados da simulação } \\
\text { mostram que os índices } \\
\text { superaram Taam e Hubele } \\
\text { utilizados na correlação. }\end{array}$ \\
\hline $\begin{array}{l}\text { Review of Multinomialand } \\
\text { Multiattribute Quality } \\
\text { Control Charts } \\
\text { (TOPALIDOU; } \\
\text { PSARAKIS, 2009) }\end{array}$ & $\begin{array}{c}\text { Sistema de Medição de } \\
\text { desempenho }\end{array}$ & $\begin{array}{l}\text { Para atingir o objetivo da } \\
\text { pesquisa, foi realizado um } \\
\text { levantamento bibliométrico. }\end{array}$ & $\begin{array}{l}\text { Dentre as variáveis } \\
\text { encontradas, destacam-se: } \\
\text { A utilização de controle da } \\
\text { qualidade na indústria da } \\
\text { saúde; } \\
\text { A relação de imprecisão com } \\
\text { o nível dos controles dos } \\
\text { gráficos. }\end{array}$ \\
\hline $\begin{array}{l}\text { Fuzzy inference to assess } \\
\text { manufacturing process } \\
\text { capability with imprecise } \\
\text { data (HSU; SHU, 2008) }\end{array}$ & $\begin{array}{c}\text { Sistema de Medição de } \\
\text { desempenho }\end{array}$ & $\begin{array}{l}\text { O modelo de avaliação fuzzy foi } \\
\text { utilizado para avaliar a } \\
\text { capacidade do processo }\end{array}$ & $\begin{array}{l}\text { Os dados obtidos foram } \\
\text { determinados a partir de } \\
\text { variações para pesquisas, } \\
\text { não representando uma } \\
\text { realidade empresarial; os } \\
\text { autores sugerem a replicação } \\
\text { em empresas com problemas } \\
\text { de produtos distorcidos. }\end{array}$ \\
\hline $\begin{array}{l}\text { Using recurrent neural } \\
\text { networks to detect } \\
\text { changes in autocorrelated } \\
\text { processes for quality } \\
\text { monitoring (PACELLA; } \\
\text { SEMERARO, 2007) }\end{array}$ & $\begin{array}{c}\text { Sistema de Medição de } \\
\text { desempenho }\end{array}$ & $\begin{array}{l}\text { Os dados foram obtidos por } \\
\text { meio de simulações, e a } \\
\text { correlação entre os indicadores } \\
\text { foi realizada por meio de } \\
\text { softwares }\end{array}$ & $\begin{array}{l}\text { Os autores sugerem a } \\
\text { validação da ferramenta, } \\
\text { porém acreditam que ela } \\
\text { possua elevado tempo de } \\
\text { processamento, e que em } \\
\text { realidades organizacionais } \\
\text { não teria boa aceitação. }\end{array}$ \\
\hline $\begin{array}{c}\text { Fuzzy estimation for } \\
\text { process capability indices } \\
\text { (PARCHAMI; } \\
\text { MASHINCHI 2007) }\end{array}$ & $\begin{array}{c}\text { Sistema de Medição de } \\
\text { desempenho }\end{array}$ & $\begin{array}{l}\text { Fazendo uso de intervalos de } \\
\text { confiança para estimar índices } \\
\text { de capacidade, foi possível } \\
\text { chegar a índices fuzzy, fazendo } \\
\text { assim a comparação dos } \\
\text { metodos. }\end{array}$ & $\begin{array}{l}\mathrm{Na} \text { prática os índices de } \\
\text { capacidade são aplicados } \\
\text { levando em conta pequenas } \\
\text { amostras, com pouca } \\
\text { variação de resultados; um } \\
\text { novo método de avaliação } \\
\text { pode contribuir elevando o } \\
\text { tamanho da amostra e a } \\
\text { precisão dos resultados. }\end{array}$ \\
\hline
\end{tabular}

Fonte: Elaborado pelos autores (2016).

A partir das variáveis preestabelecidas, é possível identificar que todos os autores tratam o tema a partir de uma visão de Avaliação de Desempenho como ferramenta de acompanhamento de resultados, sem integrar estes resultados com aspectos de gestão e aperfeiçoamento. Assim, os artigos do PB enfatizam Sistemas de Medição do Desempenho, em vez de Sistemas de Gestão do Desempenho, nos termos da classificação proposta 
por Melnyk et al., (2014), resultado este que evidencia o caráter operacional das atividades desenvolvidas por meio do Controle Estatístico de Processos.

Como resultado, destaca-se ainda a utilização de modelos teóricos realistas, que levam em conta dados obtidos a partir de simulações, como é o caso dos modelos fuzzy, sem considerar as realidades organizacionais e os atores envolvidos no contexto nos termos propostos por Ensslin et al. (2010).

\section{CONSIDERAÇÕES FINAIS}

As empresas, particularmente as de manufatura, têm na gestão de processos de fabricação seu diferencial competitivo. Os sistemas de apoio à decisão nesta área até recentemente se centravam no uso de abordagens realistas (normativistas, descritivistas) que para ambientes simples e estáveis mostraram ser de valia. Quando, no entanto, os sistemas produtivos se encontram em ambientes complexos, dinâmicos, com informações difusas, e com interesses conflitantes, estes sistemas têm seus resultados comprometidos. Para estes ambientes ter em conta as particularidades, são criados diferenciais exclusivos e geradas competências e vantagens competitivas de difícil replicação. É para estes sistemas que este trabalho se propõe conhecer o que a ciência está fazendo e propôs como objetivo geral "conhecer o que a literatura científica internacional aborda sobre o tema gestão do CEP quando analisado sob a ótica da avaliação de seu desempenho e evidenciar seus mais destacados parâmetros".

Os objetivos de pesquisa foram alcançados mediante a operacionalização da ferramenta Proknow- $C$, que sistematizou a evidenciação dos parâmetros: autores, artigos, periódicos e palavras-chave mais presentes no tema "gestão de CEP" quando analisado sob a visão de sua performance.

Os autores em destaque no portfólio são: Wen Lea Pearn, PhD, Professor of University of Maryland com 5 publicações de periódicos, Shu-Ming Chung, PhD, Professor of The University of Tokyo, com 4 publicações e Bi-Min Hsu of Departamento of Industrial Engineering and Management of University Taiwan com 3 periódicos.

Já em relação aos periódicos científicos responsáveis pelas divulgações das pesquisas, destacam-se: Quality and Reliability Engineering International, apresentando 9 publicações, seguido da Expert Systems With Applications com duas.

Outra característica analisada foram as palavras-chave no PB. Process Capability Indices, Control Carts e Process Capability index configuraram-se como as palavras-chave mais relevantes, aparecendo respectivamente em nove, seis e cinco publicações.

Os periódicos em destaque, identificados quanto ao fator de impacto foram: European Jounal of Operational Research (2,37); Expert Systems with Applications (2,00); Computers and Industrial Engeering $(1,58)$; Measurament (1,48); International Journal of Advanced Manufacturing Technology $(1,46) ;$ Quality and Reliability Engineering International $(1,19)$; Soft Computing $(1,07)$.

$\mathrm{Na}$ análise avançada das características dos artigos do PB evidenciou-se que todos os artigos fazem uso de sistemas de Medição de Desempenho, como proposto por Melnyk et al., (2014), com ênfase na utilização de modelos fuzzy, analisando indicadores operacionais sem integrar tais dados com objetivos estratégicos.

Dentre as constatações mais relevantes observadas constam as dos autores Kaya e Kahraman (2011); Haq, Brown e Moltchanova (2014); Chen, Lai e Nien (2010); Celano et al., (2011); Zhang et al., (2014), que mesmo reconhecendo a necessidade da gestão do CEP estar alinhada aos objetivos da organização e ter em conta suas particularidades se valem de abordagens realistas (normativistas, descritivistas ) e propõem modelos genéricos que omitem os valores, as preferências e as motivações do contexto onde os modelos de gestão do CEP são aplicados. Tais trabalhos fomentam a utilização de diversos indicadores, porém não há uma organização entre eles que possibilite a identificação de quais níveis estratégicos, táticos e operacionais se propõem mensurar seu desempenho, tornando estes critérios de difícil convergência com os objetivos empresariais. Os objetivos empresarias são tratados de maneira superficial nos trabalhos, e correspondem a atributos de eficiência, qualidade e elevação do desempenho, porém não há uma indicação direta de como estas preocupações puderam ser operacionalizadas.

Sugere-se para futuras pesquisas que visem à construção de ferramentas de apoio à gestão do CEP e que as mesmas adotem uma abordagem construtivista e tenham em conta as especificidades do contexto ao qual se destinam e assim assegurem a harmonia entre a abordagem com seu uso; reconheçam a singularidade do 
contexto; tenham em conta os valores, interesses e motivações do gestor para a identificação dos critérios a serem utilizados para mensurar a performance da gestão do CEP; que as escalas de mensuração (indicadores de desempenho) atendam aos fundamentos da Teoria da Mensuração; que a integração dos critérios ocorra a partir de níveis de referência estabelecidos pelo gestor; que o modelo resultante permita monitorar o status quo e guiar o processo de geração de ações de aperfeiçoamento. Em assim procedendo, a ciência estará mais se aproximando das demandas da comunidade empresarial.

\section{REFERÊNCIAS}

AHMAD, S.; ABDOLLAHIAN, M.; ZEEPHONGSEKUL, P.; ABBASI, · B. Multivariate nonnormal process capability analysis. International Journal of Advanced Manufacturing Technology, v. 44, n. 7-8, p. 757-765, 2009.

AL-REFAIE, A.; BATA, N. Evaluating measurement and process capabilities by GR\&R with four quality measures. Measurement, v. 43, n. 6, p. 842-851, 2010.

BACON, F. Novum organum (1620). PF Collier \& Son, New York, 1902.

CHANG, T. C.; WANG, K. J.; CHEN, K. S. Capability performance analysis for processes with multiple characteristics using accuracy and precision. Proceedings of the Institution of Mechanical Engineers, Part B: Journal of Engineering Manufacture, v. 228, n. 5, p. 766-776, 2014.

CHANG, Y. M.; WU, T. L. On Average Run Lengths of Control Charts for Autocorrelated Processes. Methodology and Computing in Applied Probability, v. 13, n. 2, p. 419-431, 2011.

CELANO, G.; CASTAGLIOLAB, P.; TROVATOC, E.; FICHERA, S. Shewhart and EWMA t Control Charts for Short Production Runs. Quality and Reliability Engineering International, v. 27, n. 3, p. 313-326, 2011.

CHEN, C. C.; LAI, C. M.; NIEN, H. Y. Measuring process capability index C pm with fuzzy data. Quality and Quantity, v. 44, n. 3, p. 529-535, 2010.

CRESWELL, J. W. Projeto de pesquisa métodos qualitativo, quantitativo e misto. In: Projeto de pesquisa métodos qualitativo, quantitativo e misto. Artmed, 2010.

DA ROSA, M. M.; ENSSLIN, S. R; PETRI, S. M.; ENSSLIN, L. Avaliação de Desempenho de Políticas Públicas: Construção do Conhecimento com Base na Literatura Internacional. Revista Ibero-Americana de Estratégia, v. 14, n. 3, p. 110, 2015.

DA SILVA, E. D.; PEREIRA, N. A. F. Centro de serviços compartilhados e a gestão de vínculos: uma análise integrada. Revista Alcance, 11.1. 049-064, 2009.

DUTRA, A.; RIPOLL-FELIU, V. M.; FILLOL, A. G.; ENSSLIN, S. R.; ENSSLIN, L. The construction of knowledge from the scientific literature about the theme seaport performance evaluation. International Jornal of Productivity and Performance Management, v. 64, n. 2, p. 243-269, 2015.

ENSSLIN, L.; ENSSLIN, S.R.; PINTO, H.D. M. Processo de investigação e análise bibliométrica: Avaliação da Qualidade dos Serviços Bancários. Revista de administração Contemporânea, v. 17, n. 3, p. 325-349, 2013.

ENSSLIN, L. GIFFHORN, E.; ENSSLIN, S. R.; PETRI, S. M.; VIANNA, W. B. Avaliação do Desempenho de Empresas Terceirizadas com o Uso da Metodologia Multicritério de Apoio à Decisão- Construtivista. Revista Pesquisa Operacional, v. 30, n. 1, p. 125-152, 2010.

ENSSLIN, L.; DUTRA, A.; ENSSLIN, S. R.; CHAVES, L. C.; DEZEM, V. Research Process for Selecting a Theoretical Framework and Bibliometric Analysis of a Theme: Illustration for the Management of Customer Service in a Bank. Modern Economy, v. 6, n. 6, p. 782, 2015.

GU, K.; JIA, X.; LIUB H.; YOUA, H. Yield-based capability index for evaluating the performance of multivariate manufacturing process. Quality and Reliability Engineering International, v. 31, n. 3, p. 419-430, 2015.

HAQ, A.; BROWN, J.; MOLTCHANOVA, E. A New Cumulative Sum Quality Control Scheme for Monitoring the Process Mean. Quality and Reliability Engineering International, v. 30, n. 8, p. 1165-1177, 2014.

HSU, B. M.; SHU, M. H. Fuzzy inference to assess manufacturing process capability with imprecise data. European Journal of Operational Research, v. 186, n. 2, p. 652-670, 2008. 
HSU, B. M.; SHU, M. H.; PEARN W. L. Measuring process capability based on Cpmk with gauge measurement errors. Quality and Reliability Engineering International, v. 23, n. 5, p. 597-614, 2007.

KAYA, I.; KAHRAMAN, C. Process capability analyses based on fuzzy measurements and fuzzy control charts. Expert Systems with Applications, 2011.

KHADEMI, M.; AMIRZADEH, V. Fuzzy rules for fuzzy $x$ and $r$ control charts. Iranian Journal of Fuzzy Systems, v. 11, n. 5, p. 55-66, 2014.

KEENEY, R. L. Value-focused thinking: a path to creative decision making. Harvard University Press, London, 1992.

LACERDA, R. T. D. O.; ENSSLIN, L.; ENSSLIN, S. R. Uma análise bibliométrica da literatura sobre estratégia e avaliação de desempenho. Gestão \& Produção, v. 19, n. 1, p. 59-78, 2012.

LANDRY, M. A note on the concept of problem. Organization Studies, v. 16, p. 315-343, 1995.

LIN, P. C.; PEARN, W. L. Testing manufacturing performance based on capability index Cpm. International Journal of Advanced Manufacturing Technolog, v. 27, n. 3-4, p. 351-358, 2005.

MELNYK, S. A; BITITCI, U.; PLATTS, K.; TOBIAS, J.; ANDERSEN. B. Is performance measurement and management fit for the future? Management Accounting Research, v. 25, p. 173-186, 2014.

PACELLA, M.; SEMERARO, Q. Using recurrent neural networks to detect changes in autocorrelated processes for quality monitoring. Computers and Industrial Engineering, v. 52, n. 4, p. 502-520, 2007.

PANA, J. N.; LEE, C.Y. New capability indices for evaluating the performance of multivariate manufacturing processes. Quality and Reliability Engineering International, v. 26, n. 1, p. 3-15, 2010.

PARCHAMI, A.; MASHINCHI, M. Fuzzy estimation for process capability indices. Information sciences, v. 177, n. 6, p. 1452-1462, 2007.

PARCHAMI, A.; MASHINCHi, M.; MALEKI, H. R. Confidence interval for fuzzy process capability index. WSEAS Transactions on Systems, v. 4, n. 5, p. 546-551, 2005.

RICHARDON, R. J. Pesquisa Social, Métodos e Técnicas. 3. ed. São Paulo: Atlas, 2008.

ROY, B. Decision science or decision-aid science? European Journal of Operational Research, v. 66, n. 2, p. 184-203, 1993.

SHU, M. H.; WU, H. C. Manufacturing process performance evaluation for fuzzy data based on loss-based capability index. Soft Computing, v. 16, n. 1, p. 89-99, 2012.

TASCA, J.; ENSSLIN, L.; ENSSLIN, S. R.; BERNARDETE, M. M. A. An approach for selecting a theoretical framework for the evaluation of training programs. Journal of European Industrial Training, v. 34, n. 7, p. 631655, 2010.

TOPALIDOU, E; PSARAKIS, S. Review of Multinomial Multiattribute Quality Control Charts. Quality and Reliability Engineering International, 2009.

ZHANG, M.; WANG, G.; SHUGUANG, H.E.; ZHEN, H.E. Modified Multivariate Process Capability Index Using Principal Component Analysis. Chinese Journal of Mechanical Engineering, v. 27, n. 2, p. 249-259, 2014.

WOOLURU, Y.; SWAM, D. R.; NAGESH, P. The process capability analysis - A tool for process performance measures and metrics - A case study. International Journal for Quality Research, v. 8, n. 3, p. 399-416, 2014.

WU, C. W.; PEARN, W. L. Capability testing based on Cpm with multiple samples. Quality and Reliability Engineering International, v. 21, n. 1, p. 29-42, 2005.

Revista Alcance - Eletrônica - vol. 24 - n. 3 - jul./set. 2017 